\title{
Bilimsel Aletlerin Doğu ile Batı Arasındaki Yolculuğu
}

\section{The Movement of Scientific Instruments between East and West}

\section{Scientific Instruments between East and West. Editörler Neil Brown, Silke Ackermann ve Feza Günergun. Bilimsel Aletler ve Kolleksiyonlar serisi cilt 7. Leiden/Boston: Brill, 2019, XVII+283 s. ISSN 1877-7066.}

\section{Atilla $\operatorname{Bir}^{1}(1)$}

'Prof. Dr. Fatih Sultan Mehmet Vakıf Üniversitesi, Fen-Edebiyat Fakültesi, Bilim Tarihi Bölümü, İstanbul, Türkiye

ORCID: A.B. 0000-0001-7423-7690

Sorumlu yazar/Corresponding author:

Atilla Bir,

Fatih Sultan Mehmet Vakıf Üniversitesi, Fen-Edebiyat Fakültesi, Bilim Tarihi Bölümü, İstanbul, Türkiye

E-posta/E-mail: atilabir@gmail.com

Başvuru/Submitted: 27.04 .2020 • Kabul/Accepted: 10.05.2020 • Online Yayın/Published Online: 03.07.2020

Atıf/Citation: Bir, Atilla, "Bilimsel Aletlerin Doğu ile Batı Arasındaki Yolculuğu." Osmanlı Bilimi Araştırmaları 21, 2 (2020): $423-426$. https://doi.org/10.26650/oba.728042

Uluslararası Bilim ve Teknoloji Tarihi ve Felsefesi Birliği (IUHPST) bünyesinde yer alan Bilimsel Aletler Komisyonu (Scientific Instrument Commission, SIC) 1981 yilından beri her yıl başka bir ülkede toplanarak bilgi şölenleri (sempozyumlar) tertiplemektedir. Bilimsel Aletler bilgi şöleninin 35'incisi İstanbul Üniversitesi Bilim Tarihi Bölümü tarafından, Feza Günergun'un yönetiminde 26-30 Eylül 2016 tarihlerinde İstanbul'da tertiplenmiştir. $\mathrm{O}$ tarihlerde ülkemiz sıkıntılı günler geçirmesine rağmen bu toplantıya, yarısından fazlası Türkiye ve İran'dan olmak üzere, 80 bilim insanı katılmıştır. Toplantı süresince katılımcılar özellikle İstanbul Üniversitesi bünyesinde bulunan bilimsel alet, kitap ve objelerden oluşan Bilginin İzinde sergisini ziyaret etme firsatını bulmuştur. Ayrıca tertiplenen gezilerle İstanbul'da bulunan bilimsel alet koleksiyonlarını gezebilmişlerdir. 
Tanıtılan kitap, toplantıya sunulan 50 bildirinin arasından seçilen 14 bildiriyi içermektedir. İlk bildiriler, Osmanlı coğrafyasında kullanılan aletlere ayrılmıştır. Gaye Danışan, bildirisinde Seydi Ali Reisin Mir'at-l Kâinat isimli eserinde ele alınan usturlab, rub-l müceyyeb, rub-i mukantarat, zatü'l-kürsi ve daire-i muaddil gibi beş adet seyir ve zaman ölçüm aletini karşılaştırmıştır. Benzer bir çalışmayı Atilla Polat Türkiye kütüphanelerinde bulunan pergar-l nisbe risaleleri için yapmıştır. Üçüncü bildiri Feza Günergun, Gaye Danışan ve Atilla Polat üçlüsüne aittir. Bu bildiride Osmanlı sarayındaki bir sekstant ile ilgili olarak Mühendis Feyzi Efendi'nin yazmış olduğu risale incelenmiştir. Bu risalenin kapağında yer alan portre bu kitabın cildini de süslemekte olup bu konuda rastlanmış bulunan tek örnektir. İstanbul Üniversitesi Bilim Tarihi araştırmacıları tarafından kaleme alınan her üç bildiri de, bir bilim tarihçisinden beklenen titizlikle tüm ayrıntıların üzerine gidilerek hazırlanmıştır. Bu çalışmaların tek yadırganacak tarafı aletlerin sadece birer obje olarak incelenmesi matematiksel alt yapılarına hemen hemen hiç değinilmemesidir.

Bir diğer ilginç inceleme Mahdi Abdeljaouad (Tunus Üniversitesi) ve Pierre Ageron (Caen Üniversitesi, Fransa) tarafından sunulan bildiridir. Bu bildiri bir muhtedi olan Osman Efendi bin Abdulmennan tarafından 28 Ocak 1779 tarihinde yazılan Hadiyyat al-Muhtadī isimli eser üzerinedir. Şüphesiz ki kütüphanelerede kopyaları bulunan bu kitabı daha derinlemesine incelemek ve dönemi alet teknolojisi üzerine etkisini etraflı incelemek gerekir.

Benzer bir klasik tartışma konusu Richard L. Kremer (Dartmouth Koleji, ABD) tarafından ortaya atılmıştır. Avrupa ortaçağında kullanımı ve taşıması zor olan halkalı alet (zâtü'l-halak) yerine yaygın kullanım alanı bulan Turketketum'un (Türk aleti) etimolojik kaynağı nedir? Konunun, 28 sayfa boyunca tartışıldıktan sonra bir neticeye varılmamış olması şaşırtıcıdır.

Fransa Ulusal Kütüphanesi'nin Matematiksel Aletler Kataloğu (2018) sorumlusu Anthony Turner, sunduğu bildiride doğu-batı ekseninde ölçü aletleri ve saatlerinin hangi farkı şekillerde karşımıza çıkabileceğini göstermeyi amaçlamıştır.

Hamid Bohloul (Tahran Üniversitesi) tarafından sunulan önemli bildiri on beşinci yüzyılda Uluğ Bey’in Semerkant rasathanesinde faaliyet göstermiş bulunan ve özellikle $p$ ve $\left(\sin 1^{\circ}\right)$ hesabında katılarda bulunmuş olan Gıyâsüddîn Cemşîd b. Mes‘ûd el-Kâşî’nin (ö. 832/1429) evren modelinde yaptığı çalışmalarla ilgilidir. Nuzhat al-Hadā' 'iq (Bahçelerde Gezinti) adını verdiği risaleyi büyük bir olasılıkla memleketi Kâşân’da (İran) yazmıştır. Burada geliştirdiği gezegen taşıyıcılarının yer merkezinden kayma miktarını veren Kaymalar Diski (Ṭabaq al-Manāțiq) ile gezegen kavuşumları bir arada gösteren Kavuşumlar Plakası (Lawh al-Ittiṣālāt) gezegenlerin ekvator koordinatlarını hassas bir şekilde elde edilmesini sağlar. Şu halde Kâşînin önerdiği algoritma uygulandığında 1,7 metre yarıçapındaki bir 
plaka, daire yayını dakika mertebesinde belirler. Bununla modern güneş merkezli Kopernik modelinin arifesinde İslam gökbiliminin ulaştığı sınır da sergilenmiş olur.

Teleskopun on dokuzuncu yüzyıldan önce İran'a girişiyle ilgili İran kaynaklı diğer bir önemli çalışma Seyyed Hadi Tabatabaei (Urmia Üniversitesi) tarafından sunulmuştur. Her ne kadar teleskop Galileo tarafından kullanılmaya başlandıktan 15 yıl sonra İranlılar bundan haberdar olmuşlarsa da, ilk teleskopun 1659'da - İran Darülfünunun 1851'de kuruluşundan önce- İsfahan'da bir Avrupalı misyoner tarafından imal edildiği ve kullanıldığı bilinir. Bu dönemde çevrilen çok sayıda modern astronomi kitabı arasında bir Amerikalı misyoner olan James Lyman Merrick tarafından 1841 tarihinde Farsça yazılan Risale-ye Elm ol-Nojum (Bir Gökbilim Risalesi), içerdiği ayrıntılı gezegen çizimleriyle dikkati çekmektedir.

Sismoloji, Estonya Tartu Üniversite Rasathanesinde on dokuzuncu yüzyılın sonunda bir araştırma konusu olarak ortaya çıkar. Janet Laidla (Tartu Üniversitesi) bildirisinde 1920 yıllarında Hugo Masing'in mekanik atölyesinden ünlü Golitsyn-Vilip sismograflarının hayata geçişinin öyküsünü aktarır.

Panagiotis G. Lazos (Atina Üniversitesi), George N. Vlahakis (Patras Üniversitesi) ve Constantine Skordoulis (Atina Ulusal Kapadistrian Üniversitesi) tarafindan sunulan bildiri İstanbul'da Hıristiyan Ortodoks azınlıklarına ait üç lisede halen mevcut olan bilimsel alet koleksiyonlarını tanıtmaktadır. Bunlar: Fener Rum, Zappeion (erkek) ve Zografeion (K1z) Ortodoks Devlet Liseleridir (1850-1960). Bunun haricinde Heybeliada (Halki) Ruhban okulu gelmektedir. Aletler 19'uncu yüzyılda Fransa'dan ithal edilmiş ve derslerde fizik, kimya, zooloji, astronomi, mineraloji ve anatomi bilgilerini vermede kullanılmıştır. Fener'deki okulunun kulesinde bir teleskop bile mevcuttur.

Hasan Umut (Boğaziçi Üniversitesi) ve David Pantalony’nin (Ottava Üniversitesi) ortak bildirisi, Sırp göçmeni Djordje Petrović (1927-2007) tarafından 1980 yılında Kanada Bilim ve Teknoloji müzesine hibe edilen ve çoğunlukla Osmanlı dönemine ait ölçü ve tartılardan oluşan 130 parçalık bir koleksiyonu tanıtmaktadır. Bu koleksiyonda uzunluk ölçüleri ve yer ölçümlerinde kullanılan Osmanlı çekül, yön ve seviye aletleri dikkat çekmektedir.

Bilim ve teknoloji tarihçisi Patrice Bret, bu kitaptaki bildirisinde, Fransız ordusunun Napolyon tarafından başlatılan 1798-1801 tarihleri arasındaki Mısır işgali esnasında Fransızların yaptığ bilimsel çalışmalarda kullanılmış olan bilimsel aletler konusunda ayrıntılı bilgi verilmiştir. Bu çalışmalar arasında Kahire Rasathanesinin kurulma çabası, Süveyş kanal bölgesindeki yer ölçümleri, piramitlerin yükseklik ölçümleri, telgraf şebekesinin kurulması, teleskop gözlemleri ve bilimsel alet tamir atölyesinin tesisi bulunur. 
Yansitıc1 (magic lantern) koleksiyoncusu Bernd Scholze, sinema teknolojisinin öncesinde, Imrich Emanuel Roth'un 1845-1846 yıllarında Mısır'a kadar uzanan Doğu gezisi sırasında Sultan Abdülmecit' in huzurunda yaptığı gösterilerde kullandığı el boyası yansıtıcı görüntüler konusunda bir bildiri sunmuştur.

Kitapta yer alan son bildiri Meltem Kocaman'a (İstanbul Üniversitesi) aittir. Bu ilginç incelemede Fransız J. Verdoux şirketinin temsilcisi olarak Osmanlı başkenti İstanbul'da faaliyet gösteren Optik Mağazasında satılan mallar ve özellikle en önemli müşterisi olan Osmanlı sarayına satılan aletlerle ilgili bilgiler aktarılmaktadır. Sarayın kendi kabuğuna çekildiği bu dönemde teknolojiye olan ilgisi demir yolları, uçaklar, balonlar, fotoğrafçılık telgrafçılık ve elektrikle aydınlanma gibi konularda gittikçe artmaktadır.

Şüphesiz bilim tarihçileri bir cinayeti çözmek zorunda kalan polis komiserleri gibi çalışmak ve tüm verileri en ince ayrıntılara kadar değerlendirmek zorundadırlar. Onlardan adeta zamanı durdurmaları bir büyüteçle geçmişi yorumlamaları ve sorulan soruları yanıtlamaları beklenir. $\mathrm{Bu}$ şüphesiz ki bu mesleği uygulayanlar için çok zevkli bir çabadır. Kitabın en talihsiz yönü fiyatıdır (120 £). Ülkemiz üniversitelerinde Bilim Tarihi programlarının yaygınlaşmaya başladığı günümüzde kitabın Türkçeleştirilerek topluma kazandırılması ya da yazarlara davet çıkarılarak bazı makalelerin Osmanlı Bilimi Araştırmaları dergisinde Türkçe yayınlanmasını sağlamak gerekir. 